\title{
A Readily Executable System Designed for Graduation Requirements Evaluation
}

\author{
Yuanyao Lu*, Xiaohan Guan, Xiaowei Dong, Shengnan Chen \\ School of Information Science and Technology, North China University of Technology, Beijing 100144, China \\ *Corresponding author. Email: luyy@ncut.edu.cn
}

\begin{abstract}
The evaluation of achievement of graduation requirements is the crucial procedure in the continuous improvement of the education quality of undergraduate engineering major. It supports the achievement of education objectives and plays a guiding role in the continuous improvement of teaching activities. This paper studies the establishment of an evaluation system for graduation requirement achievements. It requires to select a rational evaluation basis and use correct evaluation methods. In turn, effective evaluation results are collected and then applied to continuous improvement in teaching and learning. The achievement of graduation requirements is based on the achievement of assessment points of graduation requirements, of which the curriculum is the important part to support the achievement of graduation requirement assessment points. Combining the accreditation work of engineering education, this paper proposes an easy-to-implement design of evaluation system for achievement of graduation requirements.
\end{abstract}

\section{Keywords: Engineering education accreditation, Achievement of graduation requirements, Assessment} points of graduation requirements.

\section{INTRODUCTION}

China formally joined the "Washington Agreement" in 2016, since then a major certification system for engineering education has been started. Major certification for engineering education is an important process to promote continuous development and improvement of majors and teaching quality. The engineering education major certification is mainly based on seven general standards for effective evaluation, namely: students, training goals, graduation requirements, continuous improvement, curriculum system, faculty and conditions guarantee. Meeting the standard requirements is the "bottom line" of meeting engineering education major certification. The existing evaluation system of graduation requirement achievement is not yet mature and complete, and there are problems such as insufficient rationality and difficulty in operation, which needs further development and improvement.

\section{SIGNIFICANCE OF ESTABLISHING AN EVALUATION MECHANISM FOR GRADUATION REQUIREMENTS}

The 12 graduation requirements (12 graduate attributes in Washington Accord) achievement evaluation is an effective means to measure the quality of talent cultivation in colleges and universities [1]. The feedback results can guide the continuous improvement of education and teaching activities and promote the implementation of professional teaching reforms into actual curriculum teaching [2].

The completion of graduation requirements is a necessary condition for a bachelor's degree graduate. Therefore, establishing a reasonable evaluation system and mechanism for graduation requirements is the key to realizing the core concept of engineering education major certification [3].

The "Engineering Education Certification Standards" of the China Engineering Education Accreditation Association (CEEAA) puts forward: "The major must have clear and open graduation requirements, and the graduation requirements should support the achievement of the training goals. The major should be proved the achievement of the graduation requirements by evaluation [4]." Make clear the teaching links that support the achievement of each graduation requirements, including classroom teaching, practical teaching and etc, and finally build a supporting system of the requirements of graduation ability in teaching process [5]. Finally, it is necessary to prove the achievement of graduation 
requirements through reasonable periodic evaluation, clarify the evaluation organization, evaluation cycle, evaluation method and evaluation data source, and finally provide support for teaching quality feedback and continuous improvement [6]. The general graduation requirement achievement evaluation system is shown in Figure 1.

At present, many colleges and universities in China have a complicated design for the evaluation system of graduation requirements achievement, and it is difficult to standardize it [7]. This article explores an easy-toimplement evaluation system for graduation requirements. It can unify the major certification ideas of teachers in various teaching activities, facilitate teachers to get started quickly, participate in major certification, leaving enough flexibility for teachers to carry out their work [8].

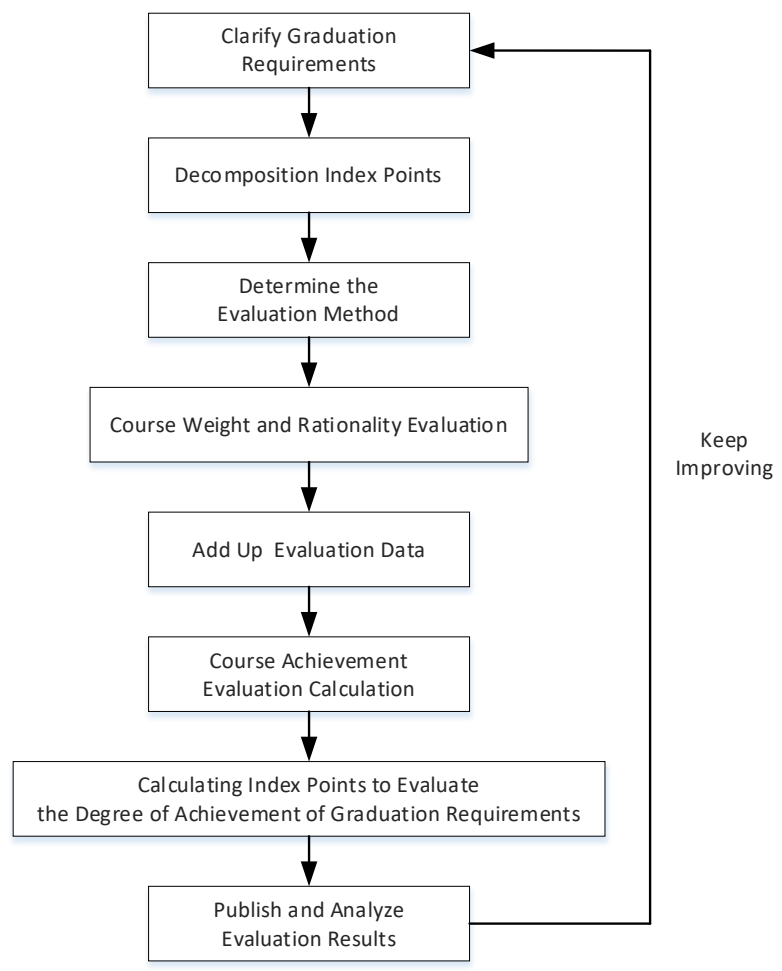

Figure 1 Evaluation system of graduation requirement achievement.

\section{ESTABLISHMENT OF AN EVALUATION MECHANISM FOR THE ACHIEVEMENT OF GRADUATION REQUIREMENTS}

The entire evaluation process of graduation requirements is established on the basis of a reasonable and detailed evaluation mechanism, including the determination of evaluation objects, evaluation cycles, evaluation institutions, selection of appropriate evaluation methods, collection of evaluation data and implementation of evaluation, then analyse it to obtain the quantitative and qualitative evaluation results, use the evaluation results for continuous improvement of teaching, and form a closed-loop evaluation system of "evaluation-feedback-improvement". The establishment of the evaluation mechanism should be simple and easy to implement, and follow the concept of student-centered, result-oriented and continuous improvement.

\subsection{Evaluation Object}

The evaluation of the graduation requirements achievement takes the students of the major as the evaluation object, the focus of the evaluation is the performance of all students, the evaluation results of the students' course links and other comprehensive practical activities are used for evaluation.

\subsection{Evaluation Cycle}

The achievement of graduation requirements is supported by the curriculum. The evaluation period for the graduation requirements of the curriculum is 2 years. Based on the evaluation results of the course achievement assessment for 2 consecutive years, the minimum value will be taken as the evaluation result of the achievement degree of the corresponding points for the course. The 
evaluation period for the graduation requirements achievement is 2-4 years, which should match the training period and according to the engineering education certification period and actual conditions.

\subsection{Evaluation Method}

The relevant teachers and evaluation teams that support the courses of graduation requirement point use a variety of evaluation methods to obtain quantitative evaluation data. The evaluation agency analyzes, compares and synthesizes various evaluation methods and the data from different sources to obtain qualitative evaluation results. The principle of formulating the evaluation method is to ensure that the obtained evaluation data is sufficiently related to the graduation requirements, using multiple evaluation methods comprehensively to get the most true and effective evaluation results.

\section{EVALUATION TYPES AND METHODS OF GRADUATION REQUIREMENTS ACHIEVEMENT}

The evaluation types of graduation requirements mainly include diagnostic evaluation, formative evaluation and summative evaluation. At present, there are two commonly used evaluation methods based on the above three evaluation types. The first one is the direct evaluation method, according to the knowledge, ability and behavior performance of students, based on the measurable learning results, directly evaluate the students' ability achievement, including classroom performance and test score analysis method, third-party professional certificate test score measurement method, and experiment or practice performance evaluation method and etc. The second one is the indirect evaluation method, in which opinion surveys or self-reports are conducted based on learning experience and behavioral performance, interview and questionnaire survey are mainly used to indirectly speculate and evaluate students' learning effect. It mainly includes graduate growth self-evaluation questionnaire survey method, graduate follow-up and survey questionnaire method, employer's job satisfaction survey method of graduates and etc. In the following sections, we will separately describe the course performance analysis method and questionnaire survey method of graduation requirements achievement evaluation.

\subsection{Achievement Evaluation of the Course Performance Analysis Method}

The graduation requirements achievement is evaluated quantitatively in the order of the achievement of the course, the points achievement of graduation requirements, the graduation requirements achievement, and the overall graduation requirements achievement of the major.

The course achievement evaluation method is based on the student's assessment results (homework, examination etc.) to calculate the achievement evaluation of the corresponding points of the course. Each graduation requirement indicator point is supported by 3 5 courses, each course can supports at most 4 points. The relationship matrix between curriculum goals and graduation requirements is shown in Table 1.

Table 1. The relationship matrix between curriculum goals and graduation requirements

\begin{tabular}{|l|l|l|l|l|}
\hline \multirow{2}{*}{\begin{tabular}{c}
\multirow{2}{*}{$\begin{array}{c}\text { The goals of the } \\
\text { curriculum }\end{array}$} \\
\cline { 2 - 5 }
\end{tabular}} & \multicolumn{4}{|c|}{ Points for graduation requirements } \\
\cline { 2 - 5 } & $1-4$ & $2-3$ & $3-2$ & $5-3$ \\
\hline Goal 1 & & & & \\
\hline Goal 2 & & & & \\
\hline Goal 3 & & & & \\
\hline Goal 4 & & & & \\
\hline
\end{tabular}

Promoting each teacher to implement assess and evaluate graduation requirements reasonably is the key to the evaluation of graduation requirements achievement. Therefore, each teacher should clarify the graduation requirements that he should undertake, including: how the course requirements reflect the graduation requirements that they should undertake, which teaching activities are used to implement the requirements and points, how to evaluate students, and how to evaluate the achievement of these graduation requirements.

Teachers can use various methods such as questionnaire survey or self-evaluation to evaluate the implementation of the graduation requirements of the course and confirm the rationality of students' assessment. Examples of evaluation are as follows: 
Table 2. Graduation requirements achievement evaluation form for students

\begin{tabular}{|c|c|c|c|c|}
\hline \multicolumn{5}{|l|}{ Course Title: XX } \\
\hline Signals and Systems & \begin{tabular}{|c|}
$\begin{array}{c}\text { Whether the } \\
\text { course } \\
\text { content } \\
\text { reflects the } \\
\text { point }\end{array}$ \\
\end{tabular} & $\begin{array}{l}\text { Whether the } \\
\text { points are } \\
\text { easy to } \\
\text { assess and } \\
\text { evaluate }\end{array}$ & $\begin{array}{l}\text { Whether } \\
\text { various } \\
\text { assessments } \\
\text { reflect the } \\
\text { points }\end{array}$ & \begin{tabular}{|l} 
Whether the \\
data and \\
results are \\
used for \\
improvement
\end{tabular} \\
\hline \multicolumn{5}{|l|}{ Graduation requirement 3} \\
\hline \multicolumn{5}{|l|}{$\begin{array}{l}\text { Point 3.1: Able to design circuits and systems for complex } \\
\text { engineering problems. }\end{array}$} \\
\hline \multicolumn{5}{|l|}{$\begin{array}{l}\text { Point 3.2: Able to design signal and information processing } \\
\text { systems for complex engineering problems. }\end{array}$} \\
\hline \multicolumn{5}{|l|}{ Graduation requirement 4} \\
\hline \multicolumn{5}{|c|}{$\begin{array}{l}\text { Point 4.1: Able to design experimental schemes for complex } \\
\text { circuit and system engineering problems, carry out experiments } \\
\text { and obtain experimental data. }\end{array}$} \\
\hline \multicolumn{5}{|l|}{$\begin{array}{l}\text { Point 4.3: Able to analyze and explain experimental data, } \\
\text { phenomena and results. }\end{array}$} \\
\hline \multicolumn{5}{|l|}{$\begin{array}{l}\text { Point 4.4: Able to draw reasonable and effective research } \\
\text { conclusions through information synthesis. }\end{array}$} \\
\hline \multicolumn{5}{|l|}{ Graduation requirement 7} \\
\hline \multicolumn{5}{|l|}{$\begin{array}{l}\text { Point 7.1: Understand environmental knowledge related to } \\
\text { electronic information engineering. }\end{array}$} \\
\hline $\begin{array}{l}\text { Point 7.2: Have environmental awareness and be able to } \\
\text { practice the concept of sustainable development. }\end{array}$ & & & & \\
\hline
\end{tabular}

\subsection{Questionnaire Survey}

The "questionnaire survey method" is used to evaluate the achievement of all graduation requirements points. The survey objects are: school students, recent graduates, previous graduates ( 5 years, 10 years, 15 years, 20 years, etc.), employers, etc. Taking electronic information engineering as an example, the employer survey questionnaire is shown in Table 3. The questionnaires for graduates are basically similar to this.

Table 3. Employer survey form for graduation requirements

\begin{tabular}{|c|c|c|c|c|c|c|c|}
\hline $\begin{array}{l}\text { XX major of XX university } \quad \text { Questionnaire of employers on the achievement of graduation requirer } \\
\text { Name of interviewed unit: }\end{array}$ & ments & & & & & & \\
\hline $\begin{array}{ll}1- & \text { Very disagree with; } \\
2- & \text { Basically disagree with; }\end{array}$ & $\begin{array}{l}\text { Degr } \\
\text { recog }\end{array}$ & & & & for & na & \\
\hline $\begin{array}{ll}\text { 4- } & \text { Basically agree with; } \\
5- & \text { Very agree with. }\end{array}$ & \begin{tabular}{l|l}
1 & 2
\end{tabular} & & & 1 & & & 5 \\
\hline $\begin{array}{l}\text { 1. Engineering knowledge requirements: able to use mathematics, natural sciences, engineering } \\
\text { foundations and professional knowledge to solve complex circuits and systems, signal and information } \\
\text { processing engineering problems. }\end{array}$ & & & & & & & \\
\hline $\begin{array}{l}\text { 2. Problem analysis ability: Ability to apply the basic principles of mathematics, natural science and } \\
\text { engineering science to identify, express, and analyze complex circuits and systems, signal and } \\
\text { information processing engineering problems through literature research to obtain effective } \\
\text { conclusions. }\end{array}$ & & & & & & & \\
\hline
\end{tabular}




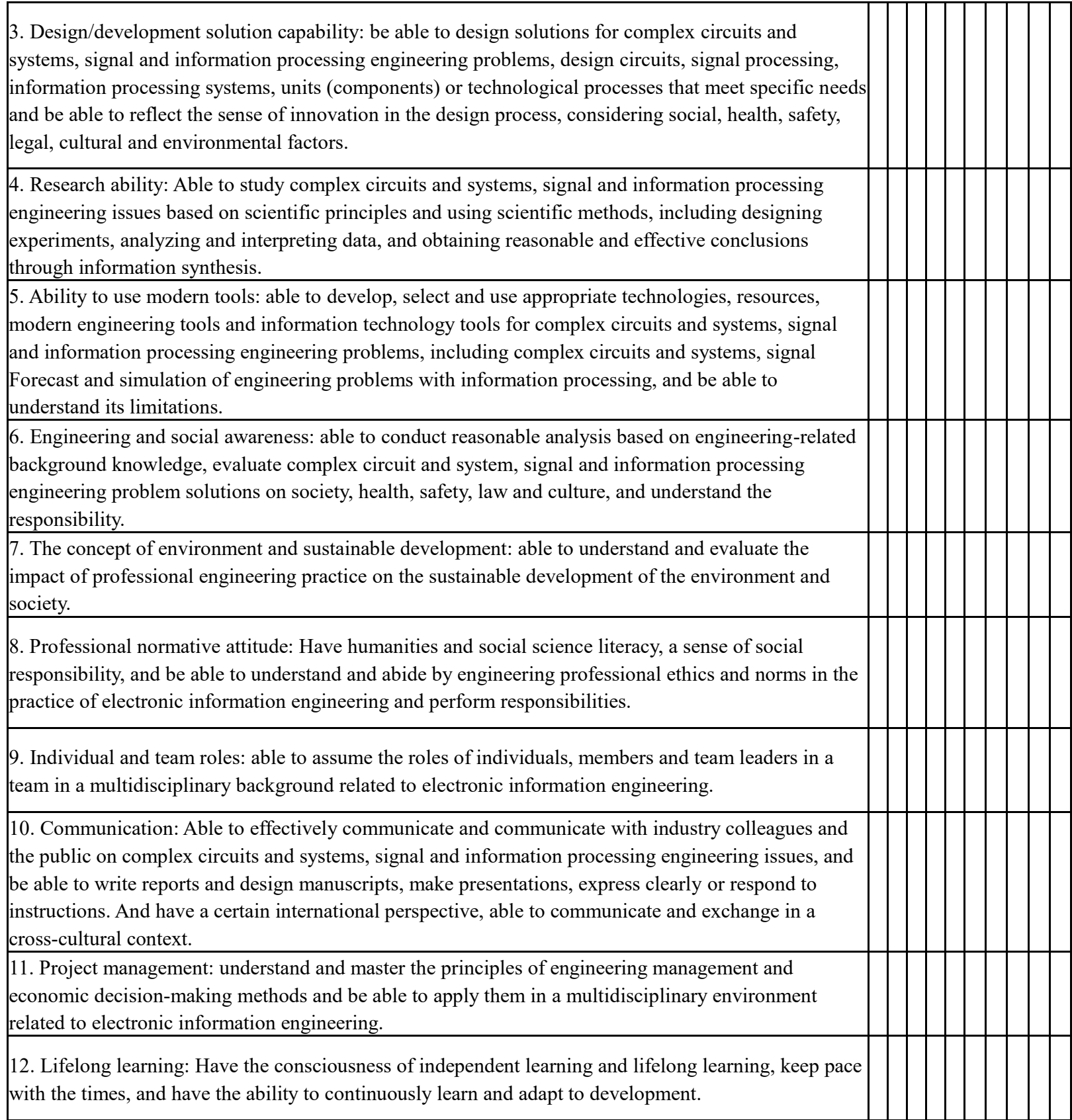

\section{CONCLUSION}

The graduation requirements achievement evaluation is an important means to measure the quality of talent cultivation in colleges and universities, an important basis for continuous major improvement, and an effective way to promote the implementation of major teaching reforms into specific courses. The graduation requirements achievement evaluation is a complex and systematic work, and a reasonable evaluation method is the prerequisite for effective evaluation. This article combines the engineering education certification work of this major to outline the establishment of an easy-toachieve evaluation system for the graduation requirements achievement evaluation. The simplification and improvement of the evaluation system should be close to the core concept of engineering education major certification. The value of the evaluation results lies in the continuous improvement of the teaching process, and the student-centered formation of a closed-loop education and teaching quality optimization process.

\section{ACKNOWLEDGMENTS}

This research was supported by the Education and Teaching Reform and Curriculum Development Research Project of North China University of Technology (109051360018XN009/008).

\section{REFERENCES}

[1] HE Jing. The Enlightenment of American 
Engineering and technology professional certification standards on China's technology professional construction [J]. Chinese Vocational and Technical Education, 2016(36): 64-68. (in Chinese)

[2] GAO Xiang-sheng, ZAN Tao, WANG Min. Study on the Method of Achievement Evaluation for Graduation Requirements According to the New Standard of Engineering Education Accreditation[J]. Education Teaching Forum, 2016(51): 206-208. (in Chinese)

[3] YANG Zhao, FU Bai-xue, LI Han-wu, ZHU Rongfu,SHI Xian-ming,ZHAO Yu-yang. Research on graduation requirement index point achievement degree evaluation supported by curriculum[J]. Journal of Heilongjiang Institute of Technology, 2018, 32(01): 62-67. (in Chinese)

[4] 2015 engineering education certification graduation requirements achievement evaluation guide [Z].2015.

[5] WANG Hong-jun. Graduation Requirements Reaching Degree Evaluaion and Analysis based on Engineering Education Accreditation OBE Philosophy[J]. Education Modernization, 2017, 4(49): 162-166. (in Chinese)

[6] Allen Estes, Stephen Ressler. Surviving ABET Accreditation: Satisfying the Demands of Criterions[J]. American Society for Engineering Education. 2007. 8.

[7] Nasser Alaraje. Resolving ABET/TAC Criteria on Continuous Improvement: Surviving ABET Accreditation $[\mathrm{J}]$. the Technology Interface Journal/Fall 2009. 10, (1). 6. 3.

[8] Graduate Attributes and Professional Competencies[C]. Washington Accord, 2021,6. DOI: http://www.ieagreements.org. 